\title{
A Culturally Relevant Teacher Professional Development for Teaching Climate Change to Native American Students
}

\author{
Anne Liu Kern ${ }^{1}$, Sameer Honwad ${ }^{2}$, Ed McLain ${ }^{3}$ \\ ${ }^{1}$ Department of Curriculum and Instruction, University of Idaho, Coeur d'Alene, Idaho, USA \\ ${ }^{2}$ Department of Education, University of New Hampshire, Durham, New Hampshire, USA \\ ${ }^{3}$ Graduate Studies-College of Education, University of Alaska Anchorage, Anchorage, Alaska, USA \\ Correspondence: Anne Liu Kern, Department of Curriculum and Instruction, University of Idaho, Coeur d'Alene, Idaho, \\ 83814, USA.
}

Received: August 6, 2017

doi:10.11114/jets.v5i10.2580
Accepted: August 16, $2017 \quad$ Online Published: August 24, 2017

URL: https://doi.org/10.11114/jets.v5i10.2580

\begin{abstract}
The science of climate change is a complex subject to teach. Teachers find climate change a challenging topic to teach due to a myriad of reasons. Gayford, 2010 describes some of the challenges teachers face while teaching climate change science as "first, the controversial nature of the topic; second, it does not relate well to the normal sequencing and division of topics within most science courses; and, third, there are important non-scientific aspects to possible solutions to the problem" (p.1191). This is a particular challenge for teachers with a diverse population. This paper reports on teachers' understanding of climate change science concepts and how to teach science with a focus on cultural relevance by participating in a three-year teacher profession development program specifically for science teachers teaching a large population of Native American students. Overall teachers demonstrated gains in understanding of how scientists access data to study climate impacts and how to present climate change science concepts that tap into culturally relevant ways.
\end{abstract}

Keywords: climate change science education, teacher professional development, culturally relevant education

\section{Introduction and Relevant Literature}

In today's political and social realm, mention of climate change is often a "hot button" topic. The science of climate change is a complex subject to teach and learn. In a recent article, the New York Times highlighted the struggles teachers and students face while trying to understand the socio-scientific issues arising from the changing climate (Harmon, 2017). The subject is imbued with teaching and learning topics that transcend disciplines and phenomena that arise from complex multilayered systems (Honwad, Mangen, \& Hoadley, 2014). Topics and issues to be addressed to help learners understand the phenomenon include climate change data (science content) as well as the socio-cultural perspectives, values, ethics (Smith \& Williams, 1999) and competing worldviews related to understanding climate change (Huckle 1995). The subject is multi-faceted and also multi-dimensional in terms of where, when, and how people learn the content matter (Smit, 2010). Increasingly, there is a recognition that teachers today should utilize collaboration techniques, such as learning across formal and informal learning environments (Barron \& Bell, 2015), to understand and resolve the environmental problems faced by local and global communities (Banks et al 2007).

Teachers find climate change a challenging topic to teach due to a myriad of reasons. Gayford, 2010 describes some of the challenges teachers face while teaching climate change science as "first, the controversial nature of the topic; second, it does not relate well to the normal sequencing and division of topics within most science courses; and, third, there are important non-scientific aspects to possible solutions to the problem" (p.1191). Johnson, 2011 further elaborates that while teaching climate change, teachers have mostly focus on the science of climate change and the influence of human activities on the climate (e.g., calculating one's carbon footprint). However, because of politicized rhetoric and the nature of lifestyle activity choices learners find it difficult to relate climate change to their everyday lives. Thus, teaching climate science and the influence of human activities on climate may not be enough to help learners understand the impacts of climate change on their everyday lives. Given the complexity surrounding topics related to climate change less than $50 \%$ of teachers in U.S. K-12 schools discuss ways to deal with climate change; less than $40 \%$ talk about the socio-economic aspects; and about $40 \%$ of teachers talk about the values, ethics and morals that surround 
the science of climate change (Johnson, 2011).

Many teachers are unclear or uncomfortable about what constitutes natural versus human-caused variation in climate; they are often poorly equipped to counter the abundant misinformation that can be found in various media outlets (Harmon, 2017). Both students and teachers often lack an understanding of such basic issues as the difference between climate and weather, the expected time frame and effects of human-caused climate change, and why peer-reviewed scientific literature is considered the primary source for the current understanding of the earth's climate system (Plutzer, et al, 2016; Wise, 2010). In contrast to schools in states where climate change is accepted as having had a material impact (e.g., Florida), secondary schools of the Intermountain West of the United States have little or no instruction in climate change in their curricula (Goodwin, 2016). As a case in point, Idaho has moved to drop climate change science from the approved state K-12 science curriculum and subsequent standards (Chow, 2017). Thus, despite the growing impact of climate change on the region, it is not uncommon for teachers in the secondary school systems of northern Idaho and northeastern Washington to avoid this topic because of its political baggage and their lack of familiarity with the relevant science.

An important concern that should be considered while teaching climate change, while recognizing the challenges related to climate change faced by all human beings, is the impact of climate change for underprivileged citizens (both socio-cultural and socio-economic status) as these impacts are more profound than for those experienced by climate privileged citizens (IPCC, 2014). Climate underprivileged citizens are those who do not have the socio-economic or cultural capacity/resources to adapt and build resilience to the impact of climate change (Foran, 2016). Hurricanes Katrina and Sandy are examples of climate change events that have severely impacted the climate underprivileged populations and exposed the gap between citizens having resources to adapt and citizens that do not have resources to respond and adapt to the impacts caused by climate change. Along with not having resources to adapt to the impacts of climate change, the climate underprivileged citizens do not have access to educational resources to help them understand the science of climate change and its effects on their everyday life.

Native American communities in the United States are considered to be some of the most vulnerable communities impacted by the circumstances of climate change (Gautam, Chief, \& Smith 2013). While the impending environmental impact of climate change is great all over the globe, researchers (Rehfeldt et al., 2006; Salathé et al., 2008) suggest that the challenge and impact of climate change among communities in the Intermountain West region of the United States is imminent and in many ways, being experienced with great impact. There are many Native American tribes that reside in this region and climate change is depleting their means to livelihood by greatly transforming plant distributions, forests, and agro-ecosystems that the communities depend on for food, shelter and clothing (Hicke, Abatzoglou, Daley-Laursen, Esler, \& Parker, 2017). There is little doubt that climate change will also increasingly affect important industries related to fisheries, forestry, agriculture, and amenity-based use of the environment in the intermountain west region (Kaur, Huggins, Rupp, Abatzoglou, Stockle, \& Reganold, 2017).

Of significance in the deliberation and efforts to address these challenges, Maldonado, Shearer, Bronen, Peterson and Lazrus (2013) document the effect of climate change on Native American communities and the serious concerns and challenges that climate change presents to land and water management. As mentioned above, Gautam, Chief, and Smith (2013) have identified Native American communities in the Intermountain west as some of the most climate underprivileged communities in the region and nation. This distinction is due not only to the particular environmental aspects of the changing Intermountain west region climate, but significantly also to the lack of educational resources and support infrastructure and systems needed to cope with the changes in the environment.

Given the rapid rate of the changing environment, it is crucial that teachers prepare students to understand and respond to these changes. While the science of climate change is central to helping Native American students understand the impact of climate change on their communities, teachers also have to align and adjust their science instruction of climate change to address and build on the socio-cultural processes in these Native American communities. These instructional practices should incorporate culturally relevant and linguistically appropriate approaches that value and respect Indigenous knowledge(s) (Castagno \& Brayboy, 2008) as foundational for classroom dynamics and in the design of the curriculum in science education. Such practices have been demonstrated to have a substantial positive influence on educational outcomes for Indigenous peoples, specifically Native Americans (Kana'iaupuni, Edward, \&Jensen, 2010; Quinton, 2013).

\subsection{Study Objectives}

This paper outlines the findings from a three-year professional development opportunity that was designed to deepen teachers' knowledge and understanding of the science of climate change by engaging them in the collaborative development of an effective, place-based climate change curriculum that is culturally aligned with the students' ethnic background. The teachers were recruited to participate in the Intermountain Climate Education Network (ICE-Net), a 
NASA funded collaborative summer professional development (PD) program developed and offered by the University of Idaho College of Education and College of Natural Resources. The ICE-Net program included residential summer events supported by yearlong follow-up PD activities held both on campus as well as at various teacher sites. The two main objectives for the program were:

- To improve the teaching of climate change science in the Intermountain West

- To understand how teachers align their curricula, content, and instructional materials with culturally relevant content knowledge and teaching methods:

To achieve these objectives ICE-Net brought together secondary school educators, science education experts, and climate change scientists from northern Idaho and northeastern Washington to help the teachers understand climate change science. The teachers also worked with both science education experts and indigenous cultural leaders and experts, and they were given examples of how to align course materials and classroom teaching practices with the Indigenous students' ethnic and tribal memberships, backgrounds, and cultures.

\section{Methods}

The overarching strategy of the ICE-Net project was to bring teachers together with project scientists (climate science experts) to explore and train the teachers in the use of readily available NASA tools to note, record, and study changes resulting from a changing climate. The ICE-Net teacher Professional Development (PD) program was offered over the course of three consecutive years, The ICE-Net PD program consisted of three one-week long summer workshops (i.e. one-week at the beginning of the summer and one-week at the end of the summer in Year I, and one-week at the end of the summer in Year II) supplemented and supported by individual and small group on-site visits and mentoring in years I, II, and III. The summer workshops were designed to provide teachers with up-to-date understandings about climate change, both globally and locally, and to expose the teachers to specific NASA tools that they would be encouraged to use in their classroom instruction.

Consistent with the project's design and supportive of the project's objective, ICE-Net teachers worked with project scientists (most often University of Idaho [UI] geography faculty) and UI science graduate students to explore and train in the use of readily available tools (in particular NASA produced products.) The NASA products included materials from the Idaho NASA Education Resource Center, products and resources from the NASA Global Climate Change Resources for Educators website. The ICE-Net PD program also showed teachers how to use change and time series visualization activities developed from Landsat and MODIS products used by graduate students associated with the project. The ICE-Net project plan included collaboration with the Earth System Science Education Alliance (ESSEA) and the use of products from My NASA Data to develop Teaching/Learning Modules (TLMs) based on the seven principles of climate science literacy (NOAA) that meet state and national standards in the Earth Sciences.

Collaboration with the teachers focused on specific issues and situations - often locally or state or regional situated - that arise in the teaching of basic earth science and that are referenced or contained in the curricula used or adopted by the various schools and districts represented by the participating teachers in the ICE-Net workshops and activities. In addition to the science content of climate change, specific attention to instructional activities that align and give rise to the culturally significance understanding of climate change were highlighted (Kern, Roehrig, Bhattacharya, Wang, Finley, Reynolds, \& Nam, 2015).

Focus and content in the trainings and activities included techniques demonstrated as useful for explaining the interplay between the socio-cultural aspects of human living and the science of climate change. The project's team of scientists and science educators collaborated with high school teachers (ICE-Net Teachers) to address such issues as the role of the sun, cosmic rays, air temperatures (as revealed through satellite and ground-instrument measures), as well as to explore and consider the evidence of the impact of greenhouse gases on the earth's past climates. Tribal community members, scientists, and educators provided lessons about the impact of climate change to the local communities, and cultural ways in which climate change is presented in local ways of life, such as stories, song, and other culturally related place-based activities (see: Kern, Roehrig, Bhattacharya, Wang, Finley, Reynolds, \& Nam, 2015).

\subsection{ICE-Net Teacher Professional Development Activities}

\subsubsection{Summer Workshops and Follow-Up Activities}

Prior to the initial summer workshop, project scientists and leaders assessed initial understandings and practices of the participating teachers to inform the development of content to be introduced and taught in the summer workshops and subsequent PD activities.

In the first summer workshops (June and August -Year I) the project team involved participants in structured instructional experiences, including presentation and lectures, interacting with computer modeling programs, and field-based examples of climate change. Effort was placed on building foundational knowledge related to climate change science, inquiry-based 
curriculum, assessment, pedagogical content knowledge (PCK), and science skills. Project scientists modeled the use of available tools and techniques appropriate for classroom and field based use to participating teachers. In addition to basic climate science content and skills, participants engaged in learning about the cultural impact of climate change on the communities in the Intermountain west.

The focus of the Year II summer workshop was to enhance the participants' understanding of climate change science and to further awareness of, access to, and the understanding and use of the computer-based databases and public software provided by NASA and available for studying climate change. Follow-up site visits provided support for further development of the curriculum and sharing of teaching approaches. Through these site visits, ICE-Net assisted teachers in translating new knowledge into practice through classroom-based mentoring by scientists, science educators, and fellow ICE-Net teachers.

\subsubsection{Online Support}

In the Year II summer workshop and in follow-up site visits, ICE-Net program leaders and scientists demonstrated and employed online teacher support programs with project teachers and in their schools and classes as a means of effectively supporting science teaching through the promotion of reflection on current teaching practices (Annetta \& Shymansky, 2006; Barab, Makinster, \& Moore, 2001; Harlen, 2004). Based on a "community of learners" model shown to be successful in enacting long-term and sustained change in science-teaching strategies and best practices (Rhoton \& Shane, 2006), the ICE-Net project set up a project website to facilitate communication and the sharing of resources between and among teachers and project staff.

\subsubsection{ICE-Net Matrix (The Teaching Learning Modules-TLMs)}

The ICE-Net project plan included collaborations with the project personnel and teacher participants to develop climate change instructional activities that drew on data sets and products from My NASA Data that would exist as a series of online Teaching/Learning Modules (TLMs). The TLMs are listed in the ICE-Net Climate Concepts Matrix. The Matrix provides lessons based on the seven principles of climate science literacy (NOAA) that met state and national standards in the Earth Sciences. The ICE-Net Climate Concepts Matrix is a publically available resource for educators via the ICE-Net website, http://icenetmatrix.com/. Publication of the matrix on the ICE-Net website allowed the matrix to be accessed by project teachers as well as other educators and interested persons, to choose climate science concepts and create classroom activities and lessons aligned to NOAA/NASA climate literacy, national science, and local science standards.

\subsection{ICE-Net PD Participants and Schools}

Over the course of three PD cycles (three summer workshops plus three years of academic year support) a total of 16 teachers, seven females and nine males, participated in the ICE-Net PD program. All of the participants taught in middle schools (MS) and high schools (HS) both on and off Indian reservations in the Intermountain West. All teachers were certified in science or technology field and had a range of teaching experience, from one to 25 years. All participating teachers taught in schools that were governed by appropriate state or federal offices. The schools designated "off reservation" and governed by local districts, are situated on the border of an Indian reservation, and serve a large population of Native American students.

Table 1. ICE-Net PD Teacher Participants

\begin{tabular}{llllll}
\hline $\begin{array}{l}\text { Participant } \\
\text { Gender/Identifier }\end{array}$ & Cohort & On/Off & MS/HS & $\begin{array}{l}\text { Yrs. } \begin{array}{c}\text { of } \\
\text { Experience }\end{array} \\
\text { Reservation }\end{array}$ & $\begin{array}{l}\text { Teaching } \\
\text { Content } \\
\text { Area Expertise }\end{array}$ \\
\hline M2 & C1/C2 & On & HS & 20 & Computer Science \\
M3 & C2 & Off & HS & 10 & Biology \\
M4 & C1/C2 & Off & HS & 18 & Geology \\
F1 & C1/C2 & Off & MS/HS & 19 & Biology Science \\
F2 & C1 & Off & HS & 4 & Biology/AP Biology \\
M5 & C1/C2 & Off & HS & 19 & Biology/Physical Sci \\
M6 & C1/C2 & On & HS & 20 & Biology/Life Science \\
F3 & C1 & Off & HS & 8 & Science/Health Sci \\
F4 & C1 & On & HS & 7 & Geology \\
M7 & C1/C2 & Off & HS & 10 & Environmental Science \\
F5 & C1/C2 & Off & HS & 4 & Biology \\
F6 & C1 & Off & HS & 25 & Environmental Sci \\
F7 & C1 & On & HS & 15 & Library Science \\
M8 & C1/C2 & On & HS & 20 & Biology \\
M9 & C1/C2 & On & HS & 15 & Physical Science \\
\hline
\end{tabular}

$\mathrm{M}=$ male, $\mathrm{F}=$ female 
Fifteen teachers started with the ICE-PD program (Year-1) and ten teachers participated in the second year PD activities. Nine total teachers participated in both years of the ICE-Net PD program (Table 1). All teachers participated in the online support and resources, contributing to the development of the ICE-Net TLMs.

\subsection{Sampling Procedures and Protocol}

\subsubsection{Measures}

All participating teachers were asked to complete standard questionnaires (Appendix A and B) on two occasions each year of their participation in the ICE-Net project, one for climate science literacy and another querying about the teacher's culturally congruent instruction practices. The questionnaires were administered a number of time during subsequent years of participation in the ICE-Net PD program - at the beginning of participation, at the beginning of each academic year while participating in the ICE-Net program, and at the end of program participation. For example, a teacher that participated in all three years of the ICE-Net program completed the questionnaires four times, a teacher that joined the projected after the second year, completed three questionnaire cycles.

At the end of each summer workshop series, all teachers were asked to provide their individual Practice-Action Goals (PAGS)-a list or summary of instructional goals for teaching climate change science in their classrooms for the upcoming academic year. These $P A G s$ provided guidance for the project leaders and research team in their development of instructional resources that would be used to develop modules for the TLMs.

In line with the ICE-Net objectives provided above, the ICE-Net project collected data that provided insight into teachers' knowledge and understanding of the science of climate change that is culturally aligned with the students' indigenous and tribal background. ICE-Net researchers and project leaders used both quantitative and qualitative data to provide a picture of the teachers' understandings. Quantitative data include descriptive statistics about the teachers' understanding of the fundamental content of climate change science and their use of culturally relevant instructional strategies. The qualitative data included teachers' logs and journals, as well as detailed self-reports by the teachers on their use of culturally relevant instructional strategies and a listing of their beginning of the year climate change instructional goals.

\subsubsection{Protocol}

ICE-Net project leaders administered surveys to the participating teachers at the beginning and end of each workshop (pre and post). The surveys focused on:

1. Content knowledge - ICE-Net Climate Change Content Knowledge Survey. (Appendix. A)

2. Culturally relevant instruction awareness - Culturally Congruent Inventory (CCI) (Sievert \& LaFrance, 2011). (Appendix B)

These surveys were administered to the teachers every year of participation over three consecutive years. The ICE-Net Climate Change Content Knowledge Survey is a 25-item multiple-choice assessment. The survey assessed fundamental content knowledge of science of climate change, such as the difference between climate and weather, and understandings of basic climate change science definitions, such as the "albedo effect"." The project team that created the ICE-Net content knowledge survey was composed of university faculty with expertise in the science of climate change, science education faculty, and other multi-disciplinary science faculty experts. Prior to administering the survey to the participating teacher, the survey was piloted with introductory geography and geology undergraduate students as a check for readability and content comprehension.

The CCI (Sievert \& LaFrance, 2011) is a published 21-item Likert scale and open-ended response questionnaire used to assess the teachers' awareness and use of culturally congruent practices in their classroom. The CCI has been used to conduct research about culturally teaching practices, mostly in science classrooms that contain a majority of Native American students. Items querying the amount of time spent examining curriculum for culturally relevant content and the amount of time given for classroom instruction for community-cultural practitioners to present relevant content or perspective comprise the Likert scale section of the questionnaire. Open-ended questions in the CCI ask teachers to list the types of culturally congruent teaching strategies they use.

\section{Results and Discussion}

The overall findings suggest that over the three-year period teachers who participated in all ICE-Net program summer workshops reported feeling well supported by the project providers, leaders, and scientists (the Project team) in addressing such key content questions as: What is a climate change? What are the causes of climate change? The data also suggest that teachers showed a positive shift toward understanding science content about climate change. However, many of the participating teachers did not feel supported in their schools or district in the areas of delivery and pedagogical strategies especially when it came to particular cultural issues and climate change science. While the 
responses provided by teachers to the annual content questionnaires each year do not show a significant change (increase) over those three years in content knowledge expressed by participants, the responding teachers did identify and discuss in their survey responses new practices and techniques they initiated or used related to climate change science and employed in the classrooms of those teachers. These new practices and applications of materials and techniques introduced in the workshops and activities indicate noticeable and significant changes in classroom based practices and curriculum. These changes are reflective of new and refined content knowledge that is supportive of and consistent with climate change science knowledge base introduced, reinforced, and modeled in the ICE-Net workshops and activities.

Given the above overall trends the "results and discussion" section starts by outlining the details of the project findings. This section first discusses the project findings regarding how the teachers fared on understanding content about climate change throughout the three-year period. We then discuss the teachers' perceptions on the impact of climate change and how the teachers thought about culturally congruent teaching practices.

\subsection{Climate Change Content Knowledge}

The year I, II, and III surveys (Appendix A) show that teachers had an uneven though generally increasing understanding in climate change (CC) content knowledge (i.e., what is climate change?). After observing and interacting with the teachers during the course of three years of professional development program, we found when it came to interpretations of climate change data (questions-2 through -4) the teachers understood how data was collected from multiple sources (e.g. ice cores, atmosphere and oceans) and how those data were interpreted as a collective. However, we did observe variation in Question 5 and Question 8. Question-5 and question-8 on the ICE-Net CC Content survey ask the teachers to interpret processes. As demonstrated in Figure 1, question-5 (The ice core shows that temperature and $\mathrm{CO}_{2}$ were correlated in the past.) the graph suggests a significant breakthrough in the teachers' expressed understanding of this foundational understanding. In responses to question-8 (Which of the following in NOT a positive feedback process?) teachers demonstrated a lower understanding of the content related to climate change particularly in year 2 , while answering most ( $75 \%$ or more) of the other questions correctly by the third year.

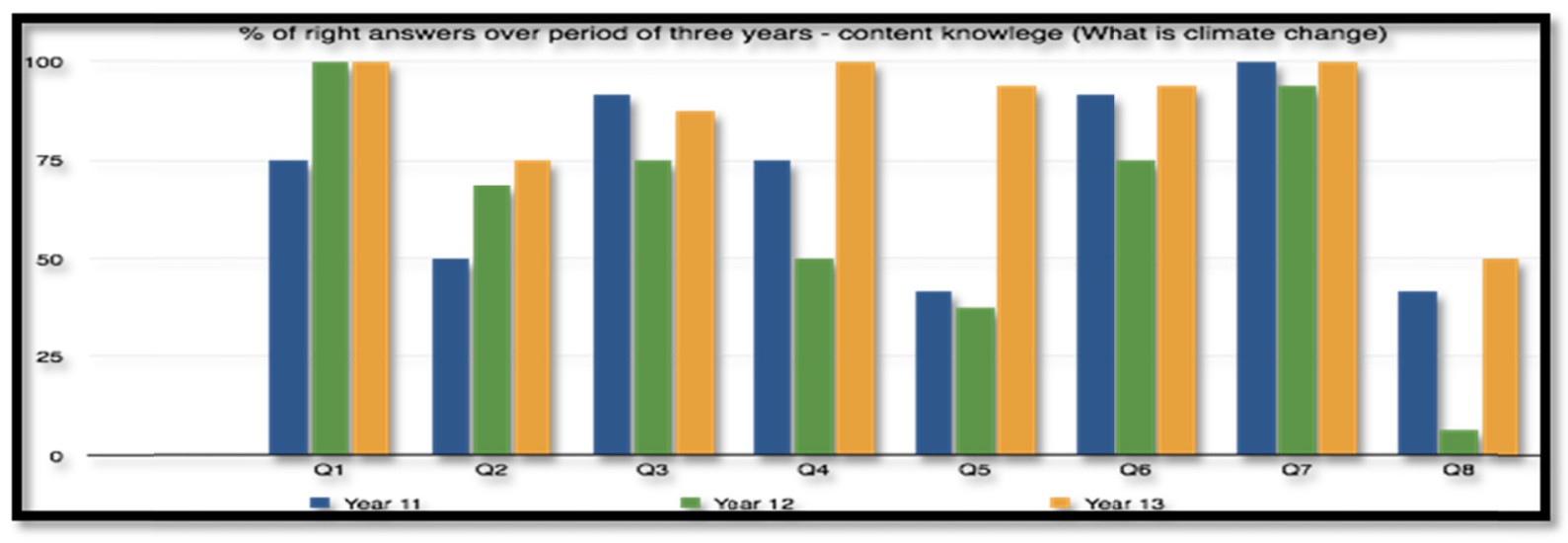

Figure 1. \% of right answers over a period of three years - content knowledge (What is climate change?)

Questions-9 through -13 tracked the teachers' perceptions about the impact of climate change.

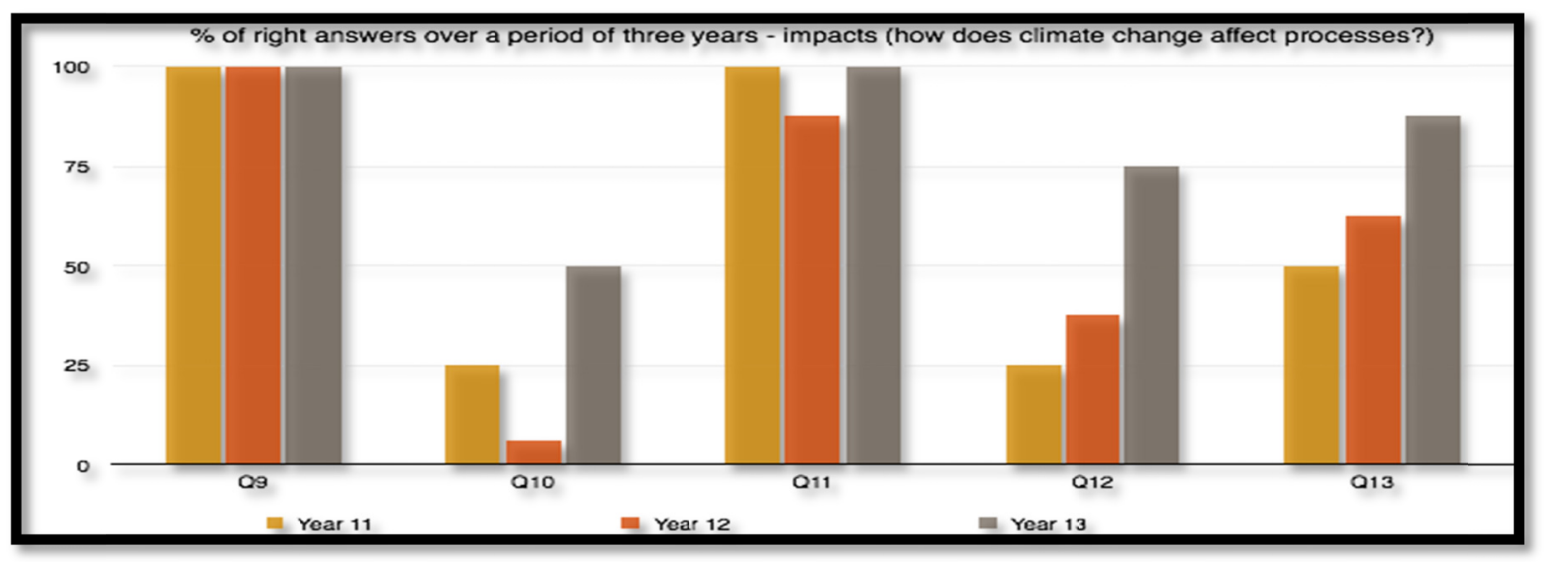

Figure 2. \% of right answers over a period of three years - impacts 
As documented in Figure 2, other than Question-10 (Which TWO processes of carbon cycling occur on the longest scales? ...) $75 \%$ or more of the teachers showed a clear understanding of the impacts that might occur because of climate change by the third year of the project.

While Question-10 (Which two processes of carbon cycling occur on the longest scales?) is a question inquiring about the process of CC, Question-12 (Greenhouse gases affect earth's temperature because...?) is associated with understanding a greater depth of the science and associated physics of radiation, specifically short-wave radiation.

Question-14 through-25 broadly focus on the causes (or the "why") of climate change and what might be some ways one can tell the impacts of the changing climate. As demonstrated in Figure 3 the teachers struggled while answering questions Questions-15 and -24.

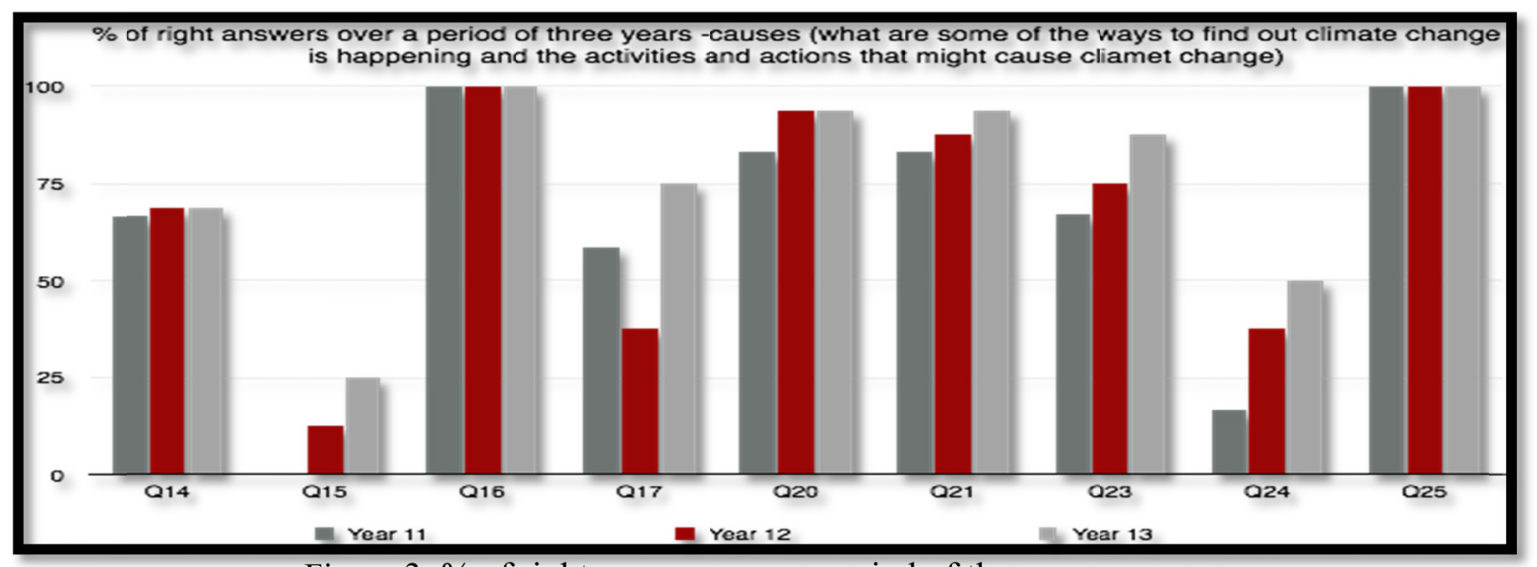

Figure 3. \% of right answers over a period of three years -causes

Question-15 was a process question, asking the teachers to interpret a graph and to state the relationship between $\mathrm{CO} 2$ methane gas and nitrous oxide. While Q24 asked for detailed Climate Change (CC) content knowledge - the teachers were asked to identify the months in which atmospheric $\mathrm{CO} 2$ concentration decreases.

All questions on the survey were tested for reliability and validity. While the teachers gave consistent responses for most questions on the survey, we found that, questions-18, -19, and -22 were not reliable questions. The teachers not only exhibited inconsistency in answering these questions but also expressed confusion and lack of clarity while answering the questions.

\subsection{Culturally Relevant Science Instruction Awareness}

As referenced earlier, along with administering the ICE-Net Climate Change Content Knowledge Survey (Appendix. A), the ICE-Net team also administered the Culturally Congruent Inventory (CCI) (Sievert \& LaFrance, 2011) (Appendix B) that asked teachers about their awareness of culturally relevant instruction and teaching. Regarding culturally congruent teaching and climate change, a review of responses to the Culturally Congruent Inventory (CCI) (Sievert \& LaFrance, 2011) (Appendix. B) indicated that most teachers did not feel confident or well supported in this area. Only 53\% of teachers over the three years of their participation in ICE-Net reported that they examine their instructional practices and classroom environment for cultural biases.

Examples of culturally relevant practices as described by participating teachers are provided below.

"I did not do any specific activities but I kept dialogue consistent throughout my classes. We discussed issues in Biology and Anatomy that dealt with cultural issues. This went from skin color physiology and language to evolutionary changes in the environment."

"When talking about photosynthesis and cellular respiration we talked about local evergreens in the area and used ponderosa pine for several specific examples which was suggested by my American Indian students"

"I use Native American terms for seasonal changes. Notably I have incorporated lunar cycles and Native American names for full moons in my classroom."

None of the teachers reported or otherwise mentioned consulting with tribal leaders for instructional or classroom management strategies.

In terms of frequency of using culturally relevant material in the classroom while teaching science our findings suggest that $33 \%$ of teachers do not use any case studies or traditional stories in the classroom, $21 \%$ of teachers said they used culturally relevant materials once a quarter or once a semester; $16 \%$ said they use culturally relevant material once a month, while $30 \%$ said they use traditional stories, case studies or other culturally relevant material once a year. Finally, 
$84 \%$ of the teachers did not incorporate native language or instruction during their interaction with students. Only $16 \%$ of the teachers incorporated native language or instruction during their interaction with students once a month, once a semester, or once a year.

As indicated by the CCI data the teachers do not feel supported or confident in designing culturally relevant classroom instruction and management strategies. However, they expressed keen desire to develop the knowledge and skills needed to understand how to design culturally relevant classroom instruction and management strategies. The quotes below highlight the point that the teachers need support in this area:

"I would like to find ways to develop a working relationship with the tribal leaders or elders. This would help me better understand the needs of my students."

"I currently have little or no knowledge about local natives and obviously need further information and training."

"I would like to be able to communicate and include Native American sciences into my curriculum and teaching more"

\subsection{Combined Findings (Climate Change Content Knowledge and Culturally Relevant Instruction)}

The overall findings suggests that while the responses provided by teachers to the multiple choice items in the post workshop surveys do not show a significant change (increase) year to year or over those three years in content knowledge explicitly expressed by the teachers. The open ended CCI survey responses related to practices and activities by the teachers in their classrooms identify and discuss in detail new practices and techniques related to climate change science that they have employed in their classrooms. These discussions and descriptions of new practices and applications of materials and techniques introduced in the summer workshops and activities indicate noticeable and significant changes or additions by those responding teachers in their classroom based practices and curricula. A number of ICE-Net teachers were observed teaching students about time scales based on moon cycles and planting/growing/harvesting that is dominant in Native American culture. In addition, some teachers organized field trips and studies where students were asked to observe and reflect on the local landscape to make sense of the impact of climate change.

Overall, the reported practices, activities, and applications of workshop derived climate change science knowledge or related materials and concepts reflect support for the climate change science knowledge and knowledge applications that were introduced, reinforced, or modeled throughout the ICE-Net PD program summer workshops and supporting activities.

\section{Conclusions and Recommendations}

The expressions of uneven and at times conflicting or inconsistent understandings of core climate science concepts by the participating teachers as documented in the survey responses strongly suggest that teachers are in need of a better understanding of how to interpret the data related to climate change. While the professional development provided by the ICE-Net team did impact the teachers' understanding of how to interpret scientific data connected to climate change science; further and deeper efforts and steps as discussed above are strongly recommended.

The ICE-Net project team found that at the start of the ICE-Net PD programs the participating science teachers and the ICE-Net scientists held or demonstrated fundamental differences in understanding of the practice of science by scientists. The teachers held specific assumptions and practices related to how scientists understand, approach, and discuss climate and climate change. The team found that focusing professional development on enhancing the teachers' ability to interpret data effectively had a profound effect on the participating teachers' understanding of the practice of doing science.

In conclusion, there is a need for more explicitly focused workshops, and discussions - direct instruction, guided discussion, as well as intentional and paired mentoring explorations that can assist teachers to understand how to interpret scientific data related to climate change. The gap between teachers understanding of how climate change data in interpreted and scientists' understanding of climate change data needs to bridged. The ICE-Net professional development model could be considered a possible framework useful to bridge the scientist-teacher gap. It is important that teachers and the scientific community be "on the same page" so as to empower the future generation to distinguish and use current and valid scientific knowledge and processes.

Even though the teachers showed measurable gains following their participation in the ICE-Net professional development activities regarding their understanding of how to interpret climate change data, as stated earlier, the participating teachers indicate in their comments and responses in the surveys and questionnaires a lack of familiarity, let alone knowledge, facility, or comfort with the use of Indigenous knowledge or mental frameworks related to climate science. Our data suggests that bringing Indigenous knowledge into the classroom to teach science is challenging for the teachers. It is challenging because the teachers are not confident in, or do not know how to gain access to Indigenous 
knowledge in the community. Access to this knowledge requires teachers to build a partnership with the community or collaborate with the community. However, most teachers tend to lack confidence and the ability to build a community partnership. This is not just an issue for the teachers in our project, but is a trend observed across countries. Teachers find it challenging to build partnerships with local communities (Gonzalez, Moll \& Amanti, 2006).

To productively assist teachers in accessing and including Indigenous knowledge in their classrooms along with helping them to build partnerships, additional professional development that explicitly focuses and exposes them to various Indigenous frameworks - ways of knowing - should be occurring (Barnhardt \& Kawagley, 2005; Coleman, 2012). Articles written in Indigenously produced publications by Indigenous peoples, on efforts and programs relating to climate change science, understanding climate change, and dealing with the impacts of climate change, and climate change mitigation should be central foci of teacher education and professional development programs for all science teachers particularly those teaching ethnically diverse students, and essential for those teaching Native American students and students from other indigenous backgrounds and cultures. Interactive, focused, open, and frank dialogue with Indigenous practitioners and researchers grounded and experienced in the concepts and practices embedded in Indigenous and American Indian "ways of knowing" may prove both challenging as well as empowering for teachers who have been less attentive to or aware of these mental models and frameworks. Noting both the commonalities as well as differences that these "other" frameworks have with "conventional" western models may very well hold positive implications for understanding and teaching the scientific and socio-scientific issues surrounding climate change.

\subsection{Research Recommendations}

We observed that teachers' interests in attending summer workshops focusing on culturally relevant teaching was inconsistent and tended to decline over the three-year period. As a result we believe that further research is needed to uncover and better understand the factors underlying the reasons for teachers' lack of motivation to embrace culturally relevant science teaching practices in their classrooms. As stated above community-school partnerships are essential in developing culturally relevant teaching practices. Next research steps or efforts may be productively directed to developing strategies to address two important aspects: 1) How do teachers align science materials to the community, and 2) What motivates teachers to invest in building partnerships with local community members.

\section{Acknowledgements}

This material is based upon work supported by the NASA Innovations in Climate Education program under Grant Number \#NNY10AT77A. Any opinions, findings, and conclusions or recommendations expressed in this material are those of the author(s) and do not necessarily reflect the views of NASA.

The authors would like to express their gratitude to Dr. Crystal Kolden and Dr. John Abatzoglou with the Department of Geography at the University of Idaho for their expertize in climate science. Additionally, we are grateful to all the teachers who participated in the ICE-Net program.

\section{References}

Annetta, L. A., \& Shymansky, J. A. (2006). Investigating science learning for rural elementary school teachers in a professional-development project through three distance-education strategies. Journal of Research in Science Teaching, 43, 1019-1039. https://doi.org/10.1002/tea.20106

Barab, S. A., MaKinster, J. G., Moore, J. A., \& Cunningham, D. J. (2001). Designing and building an on-line community: The struggle to support sociability in the inquiry-learning forum. Educational Technology research and development, 49(4), 71-96. https://doi.org/10.1007/BF02504948

Barnhardt, R., \& Kawagley, A. O. (2005). Indigenous knowledge systems and Alaska native ways of knowing. Anthropology and Education Quarterly, 36(1), 8-23. https://doi.org/10.1525/aeq.2005.36.1.008

Barron, B., \& Bell, P. (2015). Learning environments in and out of school. In L. Corno \& E. Anderman (Eds.), Handbook of Educational Psychology (Third Edition), 323-336. New York: Routledge, Taylor \& Francis.

Castagno, A. E., \& Brayboy, B. M. J. (2008). Culturally responsive schooling for Indigenous youth: A review of the literature. Review of Educational Research, 78(4), 942-993. https://doi.org/10.3102/0034654308323036

Chow, L. (2017). Idaho Drops Climate Change Language From K-12 Science Curriculum. EcoWatch (2017, February 16). Retrieved July 05, 2017, from https://www.ecowatch.com/idaho-climate-change-

Coleman, C. (2012). American Indian Ways-of-Knowing are Broader than Science. DiverseScholar 3:3.

Foran, J. (2016). Reimagining radical climate justice. Reimagining Climate Change, 150.

Gautam, M. R., Chief, K., \& Smith, W. J. (2013). Climate change in arid lands and Native American socioeconomic vulnerability: The case of the Pyramid Lake Paiute Tribe. Climatic Change,120(3), 585-599. 
https://doi.org/10.1007/s10584-013-0737-0

Gayford, C. G. (2002). Environmental literacy: Towards a shared understanding for science teachers. Research in Science \& Technological Education, 20(1), 99-110. https://doi.org/10.1080/02635140220130957

González, N., Moll, L. C., \& Amanti, C. (Eds.). (2006). Funds of knowledge: Theorizing practices in households, communities, and classrooms. New York: Routledge.

Goodwin, M. E. (2016). Climate Change Education in the United States: An Analysis of Climate Science Inclusion in K-12 State Science Standards (Doctoral dissertation, Evergreen State College).

Harlen, W. (2004). Evaluating inquiry-based science developments. Paper commissioned by the National Research Council in preparation for a meeting on the status of evaluation of Inquiry-Based Science Education,11.

Harmon, A. (2017). Climate Science Meets a Stubborn Obstacle: Students. New York Time (2017 June 4). Retrieved July 05, 2017, from

https://www.nytimes.com/2017/06/04/us/education-climate-change-science-class-students.html?_r=1

Hicke, J. A., Abatzoglou, J. T., Daley-Laursen, S., Esler, J., \& Parker, L. E. (2017). Using Scientific Conferences to Engage the Public on Climate Change. Bulletin of the American Meteorological Society, 98(2), 225-230. https://doi.org/10.1175/BAMS-D-15-00304.1

Honwad, S., Mangen, O., \& Hoadley, C. M. (2014). Learning to adapt and build resilience in the face of a changing climate.

Huckle, J. (1995). Using Television Critically in Environmental education. Environment Education Research, 1(3), 291-305. https://doi.org/10.1080/1350462950010304

Intergovernmental Panel on Climate Change (IPCC). (2014). Climate Change 2014-Impacts, Adaptation and Vulnerability: Regional Aspects. Cambridge University Press.

Johnson, C. C. (2011). The road to culturally relevant science: Exploring how teachers navigate change in pedagogy. Journal of Research in Science Teaching, 48(2), 170-198. https://doi.org/10.1002/tea.20405

Kana'iaupuni, S., Edward, B., \& Jensen, U. (2010). Culture-Based Education and its Relationship to Student Outcomes[Pamphlet]. Honolulu, HI: Kamehameha Schools Research \& Evaluation Division.

Kaur, H., Huggins, D. R., Rupp, R. A., Abatzoglou, J. T., Stockle, C. O., \& Reganold, J. P. (2017). Agro-ecological Class Stability Decreases in Response to Climate Change Projections for the Pacific Northwest, USA. Frontiers in Ecology and Evolution, 5, 74. https://doi.org/10.3389/fevo.2017.00074

Kern, A. L., Roehrig, G. H., Bhattacharya, D., Wang, J., Finley, F., Reynolds, B., \& Nam, Y. (2015). Lessons from the place: A climate change professional development for teachers in American Indian Communities. In Mueller, M. \& Tippins, D. (Eds.) EcoJustice, Citizen Science and Youth Activism: Situated Tensions for Science Education. Dordrecht: Springer International Publishing.

Maldonado, J. K., Shearer, C., Bronen, R., Peterson, K., \& Lazrus, H. (2013). The impact of climate change on tribal communities in the US: displacement, relocation, and human rights. Climatic Change, 120(3), 601-614. https://doi.org/10.1007/s10584-013-0746-z

Plutzer, E., McCaffrey, M., Hannah, A. L., Rosenau, J., Berbeco, M., \& Reid, A. H. (2016). Climate confusion among US teachers. Science, 351(6274), 664-665. https://doi.org/10.1126/science.aab3907

Polman, J. L., Kyza, E. A., O'Neill, D. K., Tabak, I., Penuel, W. R., Jurow, A. S., O'Connor, K., Lee, T., \& D'Amico, L. (Eds.). Learning and becoming in practice: The International Conference of the Learning Sciences (ICLS) 2014, 3. Boulder, CO: International Society of the Learning Sciences, 1466-1474

Quinton, S. (2013). Good Teachers Embrace Their Students Cultural Backgrounds. The Atlantic (2013 November 11). Retrieved July 5, 2017, from https://www.bing.com/cr?IG=A6EC167CF50A49548EDB6FA8C144C449\&CID=38D1C843EACE62390C03C2F 4EBC8630F \&rd=1\&h=Cf0KyIa3vcmwcpUhVobiVxFjPo-fueyDRfIVuhe3Nnk\&v=1\&r=https\%3a\%2f\%2fwww.th eatlantic.com $\% 2$ feducation $\% 2$ farchive $\% 2$ f $2013 \% 2$ f $11 \% 2$ fgood-teachers-embrace-their-students-cultural-backgrou nds\%2f $281337 \% 2 \mathrm{f} \& \mathrm{p}=$ DevEx,5064.1

Rehfeldt, G. E., Crookston, N. L., Warwell, M. V., \& Evans, J. S. (2006). Empirical analysis of plant-climate relationships for the western United States. International Journal of Plant Science, 167, 1123-1115. https://doi.org/10.1086/507711

Rhoton, J., \& Shane, P. (2006). Teaching science in the 21st century. Arlington, VA: NSTA Press. 
Salathé, E. P., Steed, R., Mass, C. F., \& Zahn, P. H. (2008). A high-resolution climate model for the U.S. Pacific Northwest: Mesoscale feedbacks and local responses to climate. Journal of Climate, 21, 5708-5726. https://doi.org/10.1175/2008JCLI2090.1

Sievert, R., \& LaFrance, J. (2011). Development, validation, and preliminary use of culturally congruent instruction survey. Orlando: National Association of Research in Science Teaching.

Smit, B., I. Burton, R. J., Klein, T., \& Street, R. (1999). The science of adaptation: A framework for assessment. Mitigation and Adaptation Strategies for Global Change, 4, 199-213. https://doi.org/10.1023/A:1009652531101

Smith, G. A., \& Williams, D. R. (1999). Ecological Education in Action. Albany, NY: State University of New York Press.

Wise, S. B. (2010). Climate change in the classroom: Patterns, motivations, and barriers to instruction among Colorado science teachers. Journal of Geoscience Education, 58(5), 297-309. https://doi.org/10.5408/1.3559695

\section{Appendix A}

\section{ICE-Net Climate Change Content Knowledge Survey}

1. According to Stephen Colbert, "is not just made up of thousands of little weathers"?
a. temperature
b. climate
c. albedo
d. Stefan-Boltzmann
e. I don't know

2. The greatest increase in temperature over the past half century has been observed:
a. over the oceans
b. in the stratosphere
c. over high latitude land masses
d. I don't know

3. Based on the graph, after 1900 , the sea level is rising at a rate of:
a. $20 \mathrm{~m} /$ century
b. $20 \mathrm{~cm}$
c. $2 \mathrm{~mm} /$ year
d. I don't know

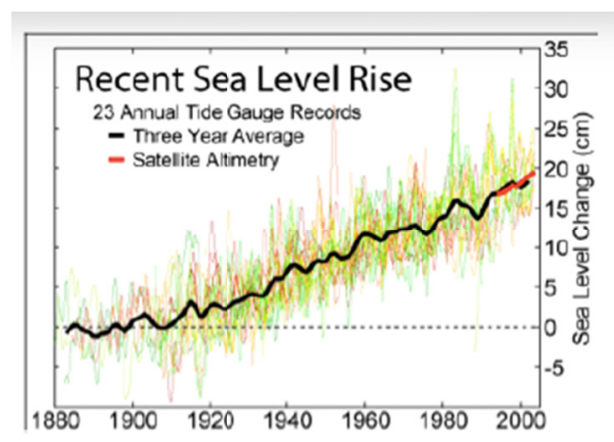

4. Based on the graph, sea ice has:
a. remained relatively stable in the $50 \mathrm{~s}$ and $60 \mathrm{~s}$
b. decreased to nearly $1 / 2$ its area in the last 40 years
c. most recently decreased at a rate of about 10 million sqkm/decade
d. all of the above
e. I don't know 


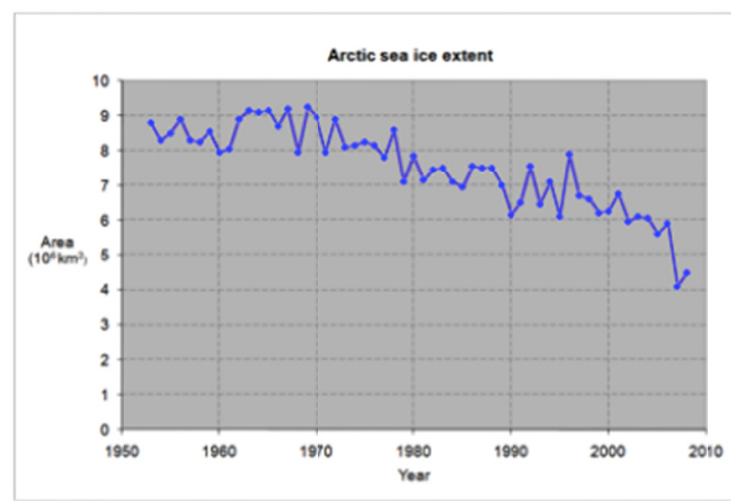

5. The ice core shows that temperature and $\mathrm{CO} 2$ were correlated in the past. The graph suggests that

a. the correlation is too rough to be meaningful

b. $\mathrm{CO} 2$ caused temperature to change

c. temperature caused $\mathrm{CO} 2$ to change

d. a mechanism needs to be found to explain the correlation

e. I don't know

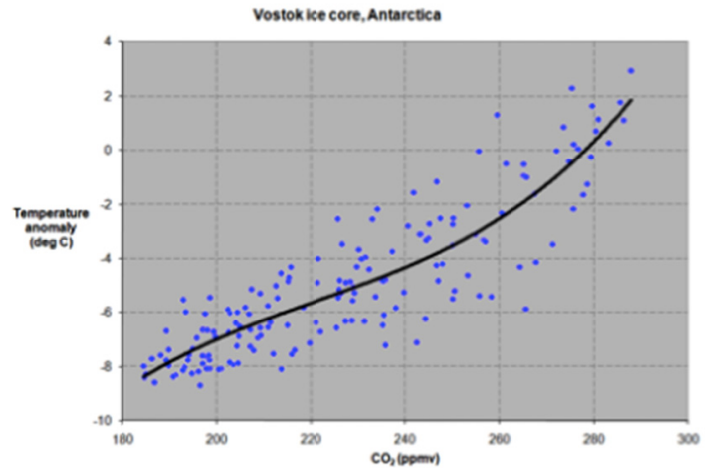

6. What is the effect of carbon dioxide in the atmosphere on climate?

a. in the past, changes in $\mathrm{CO} 2$ have been associated with large swings in the Earth's climate

b. increased levels of $\mathrm{CO} 2$ in the atmosphere are correlated with increased temperature

c. the greenhouse effect explains why climate can be affected by $\mathrm{CO} 2$

d. all of the above

e. I don't know

7. Scientists concluded that

a. fossil fuel burning is the only source of human caused $\mathrm{CO} 2$ emissions

b. $\mathrm{CO} 2$ emissions from a range of human activities are causing the increase in the atmosphere as acidifying the oceans

c. the increase of $\mathrm{CO} 2$ in the atmosphere results from natural processes in the climate system

d. scientists don't know how carbon exits or enters the atmosphere

e. I don't know

8. Which of the following is NOT a positive feedback process?
a. ice-albedo feedback
b. chemical weathering feedback
c. oceanic carbon solubility feedback
d. water vapor feedback 


\section{e. I don't know}

9. Other factors being unchanged, an increase in greenhouse gases leads to of the Earth's surface.
a. cooling
b. drying
c. warming
d. dimming
e. I don't know

10. Which TWO processes of carbon cycling occur on the longest scales?
i. weathering
ii. fossil fuel burning
iii. photosynthesis
iv. sedimentation into deep oceans
a. i\&ii
b. ii \& iv
c. $\quad$ ii $\&$ iii
d. I \& iv
e. I don't know

11. Climate change is associated with changes in the
a. past
b. present
c. future
d. all of the above
e. I don't know

12. Greenhouse gases affect the Earth's temperature because they
a. absorb all wavelengths of radiation equally
b. absorb long wave radiation
c. re-radiate shortwave radiation back to the Earth's surface
d. reflect and/or absorb shortwave radiation
e. I don't know

13. How long does it take for $\mathrm{CO} 2$ in the atmosphere to disperse?
a. days
b. months
c. one year
d. decades
e. I don't know

14. * A time series of global mean temperature is shown. The data indicates an increase in global mean temperature over the entire period of record. Provide at least two potential mechanisms that could contribute to this warming. 


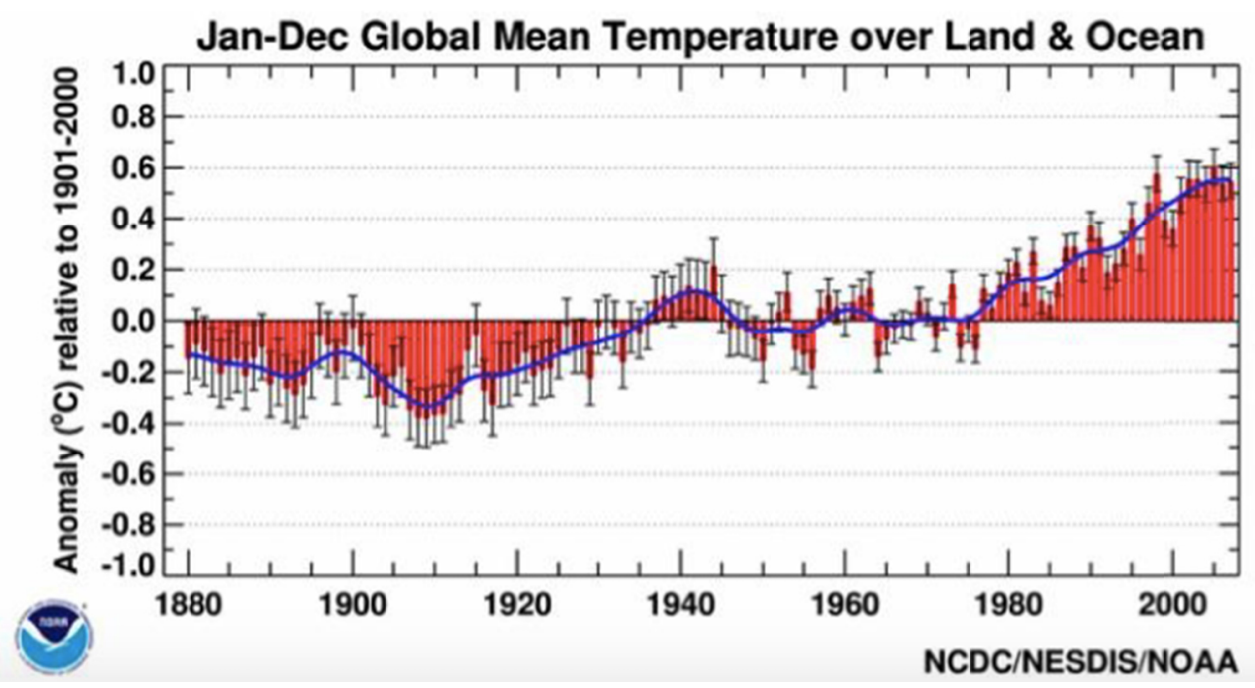

15. *The data also indicates as absence of global temperature rise between 1945 and the late 1970s. Provide as least two possible mechanisms that could contribute to this lack of warming.

16. Refer to the graphs. State the relationship between carbon dioxide, methane gas, and nitrous oxide, including any patterns you notice during the last 200 years.
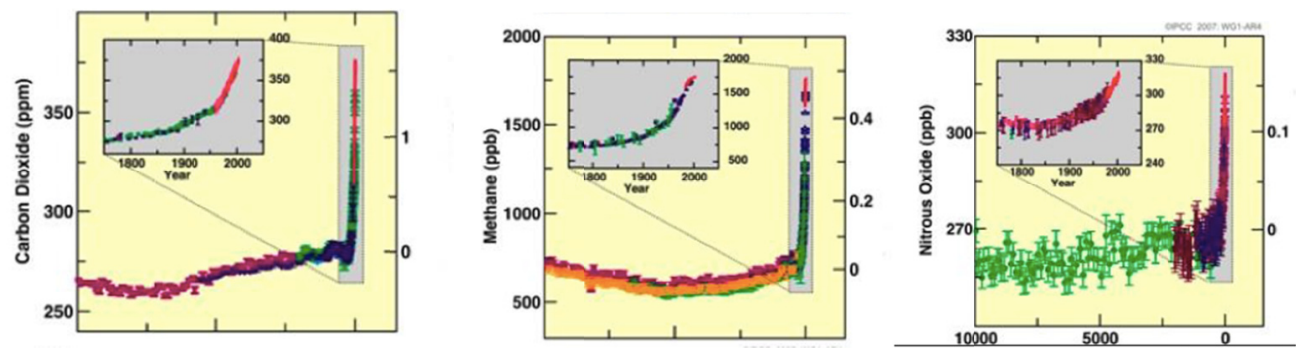

17. Which statement about greenhouse gases and aerosols in the Earth's atmosphere is INCORRECT?

Both are/have...
a. natural components of the climate system
b. increased in concentration over the last century
c. atmospheric lifetimes of generally less than two weeks
d. greenhouse gases warm the planet, while aerosols cool the planet
e. I don't know

18. The largest seasonal increase in temperature for the inland northwest of the US is projected in which season?
a. December, January, February (winter)
b. June, July, August (summer)
c. March, April, May (spring)
d. September, October, November (autumn)
e. I don't know

19. Most of the carbon on Earth is stored in which reservoir?
a. Atmosphere
b. Lithosphere
c. Dworsha
d. Biosphere
e. I don't know 
20. Hypothetical Earth 1: If white daisies were to spring up across all global land surface, the direct influence on global climate would be:
a. decreased albedo
b. increased surface temperature
c. increased cloud coverage
d. decreased surface temperature
e. I don't know

21. As a result of global warming, plant species would be expected to migrate
a. North in the Southern Hemisphere and to higher altitudes
b. North in the Northern Hemisphere and to higher altitudes
c. South in the Northern Hemisphere and to higher altitudes
d. South in the Southern Hemisphere and to lower altitudes
e. I don't know

22. Predicted hydrologic changes in climate in Idaho include all of the following EXCEPT:
a. decrease in winter precipitation
b. decrease in spring snowpack
c. increase in precipitation falling as rain
d. decrease in summer runoff
e. I don't know

23. In terms of the potential of glacial melting to raise sea level, what is most important for you to understand"
a. sea level rise and erosion can be costly and widespread
b. a catastrophic sea level rise of $225 \mathrm{~m}$ can occur in the next 100 years
c. sea level rise will mainly affect low lying foreign countries and would have no effect on the US
d. positive feedback serves to diminish the effects of glacial melting
e. I don't know

24. The seasonal decrease in atmospheric $\mathrm{CO} 2$ concentration occurs during which months:
a. Spring
b. Summer
c. April-July
d. October-January
e. I don't know

25. What is true about melting glaciers?
a. glaciers form and disappear only during Ice Age cycles, which take hundreds of thousands of years
b. glaciers might be melting at many locations around the world but the evidence is unclear
c. during the last century, glaciers in many places have shrunk
d. glaciers have disappeared entirely, making it unnecessary to consider how future climate change will affect them
e. I don't know 


\section{Appendix B}

Culturally Congruent Inventory (CCI) (Sievert \& LaFrance, 2011)

1. Please indicate to what extent you agree or disagree with the following statements.

\begin{tabular}{|c|c|c|c|c|c|}
\hline & $\begin{array}{l}\text { Strongly } \\
\text { Disagree }\end{array}$ & Disagree & Neutral & Agree & $\begin{array}{c}\text { Strongly } \\
\text { Agree }\end{array}$ \\
\hline $\begin{array}{l}\text { I. } \text { I examine my classroom environment and } \\
\text { management for cultural compatibility with } \\
\text { American Indian students on a regular basis. }\end{array}$ & 0 & 0 & 0 & 0 & 0 \\
\hline $\begin{array}{l}\text { 2. The bulletin boards/displays in my room include } \\
\text { cultural content. }\end{array}$ & 0 & 0 & 0 & 0 & 0 \\
\hline $\begin{array}{l}\text { I. examine content and instructional practices for } \\
\text { cultural bias when planning my lessons. }\end{array}$ & 0 & 0 & 0 & 0 & 0 \\
\hline $\begin{array}{l}\text { 4. I have not asked Tribal members to examine } \\
\text { content and instructional practices for cultural } \\
\text { bias. }\end{array}$ & 0 & 0 & 0 & 0 & 0 \\
\hline $\begin{array}{l}\text { 5. I rarely consult with Tribal elders, culture } \\
\text { committees or other Tribal community members } \\
\text { about content relevant to local tribes. }\end{array}$ & 0 & 0 & 0 & 0 & 0 \\
\hline $\begin{array}{l}\text { 6. I often consult with Tribal elders or other Tribal } \\
\text { community members about classroom } \\
\text { management or instructional strategies. }\end{array}$ & 0 & 0 & 0 & 0 & 0 \\
\hline
\end{tabular}

2. For any of the activities that you stated you do in your classroom, please provide details on what you did. 
3. Please indicate how often you use any of the following strategies in your instruction.

\begin{tabular}{|c|c|c|c|c|c|c|}
\hline & $\begin{array}{l}\text { Once a } \\
\text { Year }\end{array}$ & $\begin{array}{l}1 \text { or more } \\
\text { times a } \\
\text { semester }\end{array}$ & $\begin{array}{l}1 \text { or more } \\
\text { times a } \\
\text { quarter }\end{array}$ & $\begin{array}{l}1 \text { or more } \\
\text { times a } \\
\text { month }\end{array}$ & $\begin{array}{l}1 \text { or more } \\
\text { times a } \\
\text { week }\end{array}$ & Never \\
\hline $\begin{array}{l}\text { I. I use case studies that reflect local } \\
\text { Tribal concerns with science related } \\
\text { topics. }\end{array}$ & 0 & 0 & 0 & 0 & 0 & 0 \\
\hline $\begin{array}{l}\text { I. I incorporate traditional stories and } \\
\text { historical content about local Tribes in } \\
\text { my curriculum. }\end{array}$ & 0 & 0 & 0 & 0 & 0 & 0 \\
\hline $\begin{array}{l}\text { I. collaborate with Tribal members or } \\
\text { agencies on science projects. }\end{array}$ & 0 & 0 & 0 & 0 & 0 & 0 \\
\hline $\begin{array}{l}\text { I incorporate cultural items, activities } \\
\text { or practices into science content. }\end{array}$ & 0 & 0 & 0 & 0 & 0 & 0 \\
\hline $\begin{array}{l}\text { I use print, audio/visual media or web } \\
\text { resources that reflect local Tribal } \\
\text { Cultures and positions on issues. }\end{array}$ & 0 & 0 & 0 & 0 & 0 & 0 \\
\hline $\begin{array}{l}\text { 6. I incorporate class discussions that } \\
\text { reflect Native positions or perspectives } \\
\text { on ethical dilemmas or scientific } \\
\text { issues. }\end{array}$ & 0 & 0 & 0 & 0 & 0 & 0 \\
\hline $\begin{array}{l}\text { 7. I ask Tribal elders or other community } \\
\text { members to be guest teachers in my } \\
\text { classroom. }\end{array}$ & 0 & 0 & 0 & 0 & 0 & 0 \\
\hline $\begin{array}{l}\text { 8. I teach science content using a local } \\
\text { or place based context. }\end{array}$ & 0 & 0 & 0 & 0 & 0 & 0 \\
\hline $\begin{array}{l}\text { 9. I teach American Indian traditional } \\
\text { science knowledge along with Western } \\
\text { science content. }\end{array}$ & 0 & 0 & 0 & 0 & 0 & 0 \\
\hline $\begin{array}{l}\text { 10. I use open ended problem based } \\
\text { learning. }\end{array}$ & 0 & 0 & 0 & 0 & 0 & 0 \\
\hline $\begin{array}{l}\text { 11. My students have opportunities to use } \\
\text { observational learning strategies. }\end{array}$ & 0 & 0 & 0 & 0 & 0 & 0 \\
\hline $\begin{array}{l}\text { 12. I incorporate local Native language in } \\
\text { instruction and interactions with } \\
\text { students. }\end{array}$ & 0 & 0 & 0 & 0 & 0 & 0 \\
\hline
\end{tabular}

4. Please provide specific examples of any of the strategies listed above that you used in your classroom.

5. Of the activities included in this survey, are there any that you would like further information or training on? Any additional topics or ideas that were not mentioned in the survey?

\section{Copyrights}

Copyright for this article is retained by the author(s), with first publication rights granted to the journal.

This is an open-access article distributed under the terms and conditions of the Creative Commons Attribution license which permits unrestricted use, distribution, and reproduction in any medium, provided the original work is properly cited. 